\title{
Cigarette advertising in Mumbai, India: targeting different socioeconomic groups, women, and youth
}

\author{
R Bansal, S John, P M Ling
}

Tobacco Control 2005;14:201-206. doi: 10.1136/tc.2004.010173

See end of article for authors' affiliations

\section{Correspondence to:} Pamela M Ling, MD, MPH, Box 0320, University of California, San Francisco, CA 94143-0320, USA; pling@medicine.ucsf.edu

Received 29 May 2004 Accepted 9 February 2005

\begin{abstract}
Background: Despite a recent surge in tobacco advertising and the recent advertising ban (pending enforcement at the time of this study), there are few studies describing current cigarette marketing in India. This study sought to assess cigarette companies' marketing strategies in Mumbai, India.

Methods: A two week field study was conducted in Mumbai in September 2003, observing, documenting, and collecting cigarette advertising on billboards, storefronts and at point of sale along two major thoroughfares, and performing a content analysis of news, film industry, and women's magazines and three newspapers.

Results: Cigarette advertising was ubiquitous in the environment, present in news and in film magazines, but not in women's magazines or the newspapers. The four major advertising campaigns all associated smoking with aspiration; the premium brands targeting the higher socioeconomic status market utilised tangible images of westernisation and affluence whereas the "bingo" (low priced) segment advertisements invited smokers to belong to a league of their own and "rise to the taste" using intangible images. Women were not depicted smoking, but were present in cigarette advertisements - for example, a woman almost always accompanied a man in "the man with the smooth edge" Four Square campaign. Advertisements and product placements at low heights and next to candies at point of sale were easily accessible by children. In view of the iminent enforcement of the ban on tobacco advertisements, cigarette companies are increasing advertising for the existing brand images, launching brand extensions, and brand stretching.

Conclusion: Cigarette companies have developed sophisticated campaigns targeting men, women, and children in different socioeconomic groups. Many of these strategies circumvent the Indian tobacco advertising ban. Understanding these marketing strategies is critical to mimimise the exploitation of loopholes in tobacco control legislation.
\end{abstract}

ndia is the second largest producer and third largest consumer of tobacco worldwide. ${ }^{1}$ Of the 1.1 billion smokers worldwide, 182 million (16.6\%) live in India ${ }^{2}$ accounting for consumption of 102 billion cigarettes per year. Cigarettes, consumed primarily by middle and upper socioeconomic status (SES) segments, account for only one third of tobacco consumption. ${ }^{2}$ Alternative forms of tobacco, consumed by lower SES segments, such as bidis, hookah, chewing, or powdered tobacco, account for the remaining use. Previous studies have estimated that $47-65 \%$ of all men and $14-33 \%$ of all women consume some form of tobacco and 35\% of men and 3\% of women smoke. ${ }^{3}{ }^{4}$ The 2000 Global Youth Tobacco Survey (GYTS) of youth aged 13-15 years in 12 Indian states, estimated that tobacco use in any form was greater than $40 \%$ in nine north eastern states. ${ }^{5}$ The World Health Organization projects that tobacco use may account for more than 1.5 million deaths in India by $2020{ }^{6}$

In 1999, of the 200 million female smokers worldwide, 9\% lived in the developing countries. ${ }^{7}$ Given the declining markets in the developed nations, women in the developing countries present a growing opportunity to the cigarette companies. A recent editorial about the Asian market in the industry trade journal Tobacco Reporter stated: "Rising percapita consumption, a growing population and an increasing acceptance of women smoking continue to generate new demand." ${ }^{\prime 8}$ Tobacco use among women is expected to rise to $20 \%$ by 2025 in the developed and the developing countries. ${ }^{9}$

During the 1990s, there has been a steady and substantial increase in tobacco use in India. The Tobacco Institute of India reports that cigarette sales have increased by $26.5 \%$ between 1993-94 and 1997-98, and estimates that cigarette consumption will continue to increase by $5 \%$ per year. ${ }^{10}$ The increase in tobacco consumption has paralleled the increase in spending on tobacco marketing. In 1998, tobacco advertising spending amounted to $\$ 48.8$ million, a substantial increase over recent years. ${ }^{2}$ The Indian Tobacco Company Ltd (ITC), manufacturer of Gold Flake and Wills cigarettes, doubled its advertising budget from 1995 to 1999, becoming the second largest advertiser in the nation. ${ }^{11}$ ITC, a British American Tobacco (BAT) affiliate, is the largest cigarette manufacturer with $66 \%$ of the market share. Godfrey Phillips India (GPI), a Phillip Morris affiliate, and Vazir Sultan Tobacco (VST), a BAT affiliate, each have $13 \%$ of the total market share. Golden Tobacco Company (GTC) has $8 \%$ of the market share.

Although tobacco has a longstanding history in India, tobacco regulation and legislation is a recent phenomenon. It began in 1975 with the Cigarettes Act stipulating a statutory warning "cigarette smoking is injurious to health" on cigarette packets. In 1998, the Advertising Standards Council of India voluntary code prohibited advertising to underage consumers, suggestions that using tobacco products is safe, healthy or popular; enhancing courage, or featuring the young. However, this voluntary code by a self regulating body of the advertising industry does not include a means of enforcement. In 2000, The Cable Television Networks (Amendment) Act abolished direct and indirect

Abbreviations: BAT, British American Tobacco; GPI, Godfrey Phillips India; GTC, Golden Tobacco Company; GYTS, Global Youth Tobacco Survey; ITC, Indian Tobacco Company; SES, socioeconomic status; VST, Vazir Sultan Tobacco 
tobacco advertising on cable channels. ${ }^{2}$ More recently, the Indian government passed the Cigarette and other Tobacco Products (Prohibition of Advertisement and Regulation of Trade and Commerce, Production, Supply and Distribution) Act, 2003. This Act, in effect since l May 2004, prohibits all tobacco advertising except at point of purchase, bans tobacco sponsorship of all events, restricts tobacco sales to minors and near educational institutions, prohibits smoking in public places, and mandates indication of nicotine content and statutory warning on all packages. ${ }^{12}$ The impact of this Act on advertising practices remains to be seen.

Despite increasing tobacco use among Indian men, women, and children, there are few studies assessing tobacco marketing strategies in India. ${ }^{13}{ }^{14}$ An understanding of the current cigarette marketing environment is necessary to implement effective tobacco legislation or to design successful intervention programmes to combat increasing tobacco use. In this study, we sought to identify the marketing strategies of cigarette companies in Mumbai, India, their apparent target populations, and the strategies tobacco companies appeared to be developing in anticipation of the implementation of the Cigarettes and Other Tobacco Products Act, 2003 in May 2004.

Tobacco companies in India appear to have segmented the market in Mumbai with different strategies and brands for people of high and low SES. Tobacco advertising is readily visible and utilises billboards, bus stops, print, and point of sale. The prominent advertising themes are aspirational, associating cigarette brands with success, wealth, achievement, bravery, and western lifestyles. Women are featured in cigarette advertisements and may be targeted indirectly using images of style, culture, elegance, and via "light" brand extensions. Youth are potentially exposed to substantial amounts of cigarette advertising at point of purchase. For example, cigarettes and cigarette advertisements are placed in close proximity to candies and snacks. Many of these strategies can facilitate attempts to circumvent the advertising ban.

\section{METHODS}

We conducted a two week field study in Mumbai, India in September 2003. We selected Mumbai as it is a major Indian metropolis with 13 million culturally and socioeconomically diverse inhabitants representing a vast market for most businesses. The city is also deemed the commercial capital of the country, offering high advertising avenues. We identified a thoroughfare that ran through higher SES areas and another that ran through lower SES areas. Since there are little data in India that differentiates areas in the city based on SES segments, we identified the areas based on information from local sources. One researcher performed a preliminary survey of these areas to identify the most advertised brands. Subsequently, she travelled on both these thoroughfares observing and documenting all forms of cigarette advertisements, including billboards, storefront signs, and point of sale displays.

We collected tobacco advertisements from print material published during the same time period as the field data collection. We reviewed the popular national newsmagazines, India Today and Outlook, the number one and number six English urban magazines per the 2003 National Readership Survey, Bollywood film industry magazines (Filmfare and Stardust) and women's magazines from April to September 2003. In addition, we collected tobacco advertisements from newspapers including Times of India, the number one national English newspaper, its local edition Bombay Times, and Mid Day, Mumbai's second most selling newspaper, from 4-21 September 2003. ${ }^{15}$ Cigarette advertisements were collected using digital photography and by procuring print copies when available. In addition, one of the authors (SJ) provided us with local contextual information and past advertisements from her personal collection.

The advertising campaigns were classified by brand and by advertisement placement and content. For example, we observed if the advertisements were predominantly placed in high or low SES areas, placement at point of purchase in terms of height and accessibility to children, and placement in magazines with female target audiences. Two different researchers reviewed the advertisements and described the presence of major elements, such as colour, trademark/logo use, product depiction, complementary items, health warning, setting, activity featured, number and sex of people, use of product by male or female, health reassurances, purchase incentives, and values (such as beauty/glamour, relaxation/ escape, romance, women's liberation, physical activity, success, or wealth). Differences between the advertising content for different brands and for different SES segments of the cigarette market were noted. Differences in interpretation were resolved by utilising a third reviewer or by gathering additional data. The results of this advertisement analysis were triangulated with supplemental data sources, including review of the published scientific literature, internet searches, published and unpublished prevalence surveys, newspaper articles, secondary sources, field observations, and informal queries of tobacco vendors regarding their cigarette sales practices.

\section{RESULTS}

\section{Major brands and their advertising campaigns}

Of the four major cigarette manufacturers, ITC and GPI were the most visible tobacco advertisers in Mumbai. Of the ITC brands, we observed advertising for the recently launched Wills Insignia in the super premium segment, Wills Classic/ Milds, Wills Navy Cut, Wills Silk Cut, and Gold Flake/Lights in the premium segment and Bristol in the "bingo" (plain segment cigarette brand competing with bidis and sold in mini-packs of 10) segment. GPI's major advertised brands included Four Square in the premium segment and Red and White in the bingo segment. Table 1 summarises the major cigarette brands by market segment.

\section{Advertisement channels}

We observed cigarette advertisements along the two thoroughfares on large billboards, smaller posters on street lampposts, and on the front of bus stop shelters. Mobile billboards on the back of trucks were placed at major traffic crossings, usually next to the competitor's advertisement, during rush hour traffic. In addition, a large number of storefront signs were actually cigarette advertisements (fig 1) (to view figs 1-10 please visit the Tobacco Control website-http://www.tobaccocontrol.com/supplemental). Posters advertising cigarettes were also displayed by street side vendors and on the carts of mobile vendors. Cigarette advertisements were seen in newsmagazines and in Bollywood industry magazines. We did not observe any advertising in newspapers or women's magazines. However, we did obtain a copy of an insert titled "Understanding Women" in Mid Day from April 2003 launching Platinum Cigarettes, a premium brand of Golden Tobacco Company.

Wills Insignia, Wills Silk Cut and Gold Flake/Lights were advertised on billboards only in high SES areas whereas Bristol, a bingo segment brand, was advertised on billboards predominantly in low SES areas. On Marine Drive (high SES area), there was a stretch of street lamp posters for Wills Classic cigarettes followed by five large billboards advertising Wills Clothing. GPI's premium brand Four Square was 
Table 1 Major segments, brands, and advertising campaigns in Mumbai, India

\begin{tabular}{|c|c|c|c|}
\hline Segment/brand & Advertisement description & $\begin{array}{l}\text { Advertised in higher/lower } \\
\text { SES area }\end{array}$ & Present in print \\
\hline $\begin{array}{l}\text { Super premium } \\
\text { ITC Insignia. Cost: Rs } 100 \text { for } 20\end{array}$ & $\begin{array}{l}\text { "Where quality touches infinity", "redefine } \\
\text { perfection" }\end{array}$ & Higher & India Today, Business Today \\
\hline \multicolumn{4}{|c|}{ Plos } \\
\hline $\begin{array}{l}\text { ITC Wills Classic/Mild Filter: King } \\
70-74 \text { mm. Cost: Rs60 for } 20\end{array}$ & "Discover a passion" & Higher & None \\
\hline $\begin{array}{l}\text { ITC Wills Navy Cut Filter: }<70 \text { mm. } \\
\text { Cost: Rs46 for } 20\end{array}$ & "Made for each other" & Higher & None \\
\hline $\begin{array}{l}\text { ITC Wills Silk Cut Filter: Actech. } \\
\text { Cost: Rs } 46 \text { for } 20\end{array}$ & "A blend so right a filter so fine" & Higher & None \\
\hline $\begin{array}{l}\text { ITC Gold Flake/Lights Filter: Regular } \\
68 \mathrm{~mm} \text {. Cost: Rs } 24 \text { for } 20\end{array}$ & $\begin{array}{l}\text { "It's Honeydew Smooth", Smooth, exquisite, } \\
\text { timeless. But then, all art is" }\end{array}$ & Higher and lower & $\begin{array}{l}\text { The Week, Business India, India } \\
\text { Today, Filmfare }\end{array}$ \\
\hline $\begin{array}{l}\text { GPI Four Square Filter: Regular. } \\
68 \text { mm Cost: Rs } 24 \text { for } 20\end{array}$ & "Man with the smooth edge" & Higher and Lower & Outlook, Filmfare \\
\hline \multicolumn{4}{|l|}{ Bingo* } \\
\hline ITC Bristol & "Rise to the taste" & Higher and Lower & None \\
\hline $\begin{array}{l}\text { GPI Red and White. } \\
\text { Cost: Rs } 14.50 \text { for } 10\end{array}$ & $\begin{array}{l}\text { Text in Hindi "Hum red and white peene } \\
\text { walon ki baat hi kuch aur hai" }\end{array}$ & Higher and Lower & Stardust film magazine \\
\hline VST Charms & "The taste that sets you free" & Lower & \\
\hline GTC Platinum. Cost: Rs 17.50 for 10 & "Smoother than gold" Launched in 4/03 & None & Mumbai Mid Day insert \\
\hline
\end{tabular}

GPI, Godfrey Phillips India, Ltd; GTC, Golden Tobacco Company; ITC, Indian Tobacco Company; VST, Vazir Sultan Tobacco Company.

*Smaller plain segment cigarettes that compete in the bidi (hand rolled cigarettes) segment.

US\$1 = approximately Rs 45 .

advertised both on billboards and bus stop shelters in higher SES areas. Bus stop shelters in both high and low SES areas displayed Red and White advertisements but there were no billboard advertisements. Storefront signs and posters in both areas advertised all the brands (except the superpremium Wills Insignia and premium Silk Cut brands) (table 1).

\section{Advertisement content \\ Premium brands}

The four square advertising campaign consists of black and white photographs depicting "the man with the smooth edge" holding a red square accompanied by a woman (fig 2). All the advertisements are set in affluent and recognisable surroundings in India.

The Gold Flake advertising campaign uses images associated with the arts, such as a violin or a saxophone, with a gold and red colour scheme layout (fig 1). The Wills campaign includes many brand extensions. The super premium brand Wills Insignia's advertisement features an open pack of cigarettes on a navy blue background with the byline "where quality touches infinity". In the premium segment, Wills Classic and Wills Milds were advertised on storefront signs illustrating horses and the byline "discover a passion". Wills Navy Cut advertising campaign portrays a man and a woman together under the slogan "made for each other"(fig 3). Wills Silk Cut, "a cut so right, a blend so fine", advertising campaign features an open pack of cigarettes on a sky blue background (fig 4).

\section{Bingo segment brands}

The Red and White cigarette campaign advertisements are set in nature, lack human models, and depict images such as airplanes reaching for the skies (fig 5). The Red and White campaign was the only one that used text in Hindi. The text "hum red and white peene walon ki baat hi kuch aur hai" denotes that people who smoke Red and White belong to a league of their own.

In the bingo segment, ITC markets Bristol cigarettes. The Bristol advertisements have a brown and gold colour theme and spotlights to highlight the product and the slogan "rise to the taste" (fig 6).

\section{Themes and targets identified in cigarette advertisements}

Cigarette smoking and aspiration

A common theme among the Four Square, Gold Flake, Red and White, and Bristol campaigns is that of aspiration. The premium segment brands, Four Square and Gold Flake, utilise images that portray concrete images of affluence and westernisation. For example, the Gold Flake campaign utilises images of art and music that depict luxury and wealth in the Indian culture. The western musical instruments featured in the campaign reflect an experience only the rich and westernised Indians can relate to but others aspire towards. Similarly the rich and successful "man with the smooth edge" of the Four Square campaign represents a small minority of the Indian population, but a common ideal for educated (higher SES) youth.

Both the bingo segment (lower SES) campaigns for Bristol and Red and White brands associate smoking with aspiration. They use symbolic images of success without specific references to wealth or a western lifestyle. The Bristol campaign entreats the viewer to "rise to the taste" with images of steps that lead to a pack of Bristol. The Red and White campaign depicts airplanes reaching for the sky or a flag on the mountain summit with the text denoting that people who smoke Red and White belong to a different league. The Red and White Bravery Awards that recognise members of the community who display either acts of physical bravery or acts of social courage reinforce the message conveyed in these advertisements. ${ }^{16}$

\section{Women in cigarette advertising}

Women play a key role in Godfrey Phillips' Four Square advertising campaign. Although the "man with the smooth edge" is the central character in the Four Square advertising campaign, an attractive woman always accompanies him. The female model is an attractive, elegant Indian woman dressed in either westernised Indian clothing or western clothing. The woman's face is visible while a newspaper either hides the man's face or he has his back to the viewer.

The Gold Flake campaign employs images that create an association with the arts such as a paintbrush, a violin, a saxophone, and a red scarf, and a slogan "smooth, exquisite, timeless but then all art is". These images create an aura of 
elegance, culture, and style-associations that are used to allure women to cigarette smoking. ${ }^{9}$ ITC has also launched a light version of its Gold Flake brand.

In April 2003, the Golden Tobacco Company launched Platinum cigarettes in Mumbai with an insert titled "Understanding Women" in the top selling Mumbai based newsmagazine Mid Day. The brand named Platinum, smoother than gold, capitalises on the new fad of platinum jewellery in India. The insert articles discussed the new woman, women and sex, women and power and every page contained an advertisement of platinum cigarettes with differing slogans-for example; "impeccable style - incredible price there is a price to elegance, style and confidence, Rs. 17.50; where can you buy precious metal for Rs. 17.50 - at your local panwalla [vendor selling pan (betel leaf) and tobacco products]" (fig 7).

\section{Appeals to minors}

Tobacco companies have adopted various strategies to target children and adolescents indirectly since sale of tobacco products to minors became illegal in May 2003. Marketing to minors occurs at many levels. Point of sale marketing is probably the most prominent strategy in India, where retail outlets for tobacco range from the street side peddler to convenience stores to specialty stores. The street side peddlers abound in India; they usually sell all forms of tobacco products, in addition to confectionary goods, fast food, drinks, etc. Thus their customers are of all ages and both sexes. Frequently, the tobacco products are placed next to candies. Posters advertising cigarettes are displayed prominently at low heights. Both tobacco product and promotion placement at these retail outlets are easily accessible to minors (fig 8).

Convenience stores comprise the other major retail outlet. The majority of these stores support storefront signs that display a cigarette advertisement with a byline containing the name of the store. These stores sell common household goods ranging from food staples to snacks to hygiene and stationery products. Commonly these stores also sell tobacco products, and if tobacco products are sold they are often displayed prominently.

Lastly, we observed posters advertising products for children placed next to cigarette advertisements. At one point of sale display, posters advertising Sunfeast biscuits, an ITC product, for children were placed below and over posters for the ITC premium cigarette Gold Flake (fig 8). The cigarette pack image is visible next to the biscuits and an offer for free comic books at a low eye level. The street vendor reported that he had been paid additional money to display the Sunfeast poster next to the cigarette advertisement. ITC employed the same strategy in the 25 August 2003 issue of India Today, where an advertisement for Sunfeast biscuits is adjacent to the advertisement for Gold Flake cigarettes (fig 9). Sunfeast advertisements use colours similar to the Gold Flake advertisements and carry a prominent ITC logo creating a connection between their cigarette products and other consumer goods.

\section{DISCUSSION}

The tobacco industry is pursuing many sophisticated marketing practices in India that have been documented in other parts of the world. ${ }^{17-25}$ However, our observations draw attention to some unique strategies cigarette manufacturers are using to reach different SES groups in India. For example, while aspiration is a common theme in both the higher SES premium (Four Square and Gold Flake) and the lower SES bingo segment (Red and White, and Bristol) brand advertising, we found cigarette advertisers use concrete and more western images of success to market the premium segments and more abstract images of success to advertise the bingo segment products. Indirect advertising is also being used to promote the association between smoking and success amongst the lower SES population. Since 1990, Red and White has sponsored the national bravery awards to recognise members of the community for acts of courage and bravery. Today, the Red and White bravery awards are given in nine Indian states and have been expanded to include a social service award and a lifetime achievement award. ${ }^{16}$ Prominent members of the community or political leaders usually present these awards. Although there are millions of consumers in the lower SES market, the average consumer consumes very little on an individual basis and his purchasing capacity is low. Both the manufacturers and retailers have developed tactics to circumvent this barrier. In addition to creating the bingo segment priced to compete with the bidis, cigarette manufacturers also produce smaller packs of 10 cigarettes, which increase sales among their adult consumers and cater to groups with low incomes such as children and women. Furthermore, retailers sell individual cigarettes, especially for the premium segment brands.

Current advertising strategies targeting women in India appear to be indirect. The Indian female target segment is composed of two major groups. One group comprised rural women or women of lower SES segment in urban centres who chew tobacco or smoke bidis-for example, in Mumbai $56 \%$ of women chew tobacco. ${ }^{26}$ These women are addicted to tobacco and although tobacco use is socially acceptable, cigarette smoking is not. If smoking becomes more socially acceptable for women, as it has in other countries, this is a prime target segment for cigarettes. The other female target group comprises women of a higher SES status who aspire towards a western lifestyle, such as those who work for the multinationals, media, or those who are studying in schools of mass communication and international organisations. ${ }^{27}$ Accordingly, women featured in the premium segment Four Square campaign and are portrayed in a stylish western image. The Gold Flake advertising campaign uses images of art, and a light version of the brand has been developed. Use of images depicting sophistication, sexual allure, light brands, and an association with the arts ${ }^{9}$ are strategies used to target women when depiction of women smoking cigarettes is not culturally acceptable. The lack of success of the Platinum campaign, evidenced by a lack of current advertising or product availability in Mumbai, launched in a newspaper insert entitled "Understanding Women" suggests that the Indian female target market is not ready for direct marketing to women. Similarly, there were no cigarette advertisements in women's magazines. Per a 2003 WHO study on portrayal of tobacco in Indian Cinema, tobacco consumption by females in contemporary films is $2.5 \%$ compared to $8 \%$ in earlier films. However, whereas earlier films portrayed either village women or vamps smoking, contemporary films portray middle class women. ${ }^{28}$ Interestingly, women who are either socially conscious or politically active in real life are portrayed smoking. For example, Shabana Azmi, the veteran actress and Member of Parliament, was shown smoking in the movie God Mother, with State Express 555 cigarette brand prominently displayed in several scenes. ${ }^{29}$

Furthermore, as seen in other nations, ${ }^{30}$ point of sale advertising is being used to target children and adolescents, a population segment that provides a lucrative and long term market. In 2001, cigarette sales to minors and tobacco sponsorship of sporting events was banned. Since then point of sale marketing has become the major mode of marketing to children. With 1.2 million retailers, ${ }^{31}$ India has an extensive network of tobacco sellers across the nation. Point of sale advertising is already a prominent feature at 
these outlets. The tobacco industry also provides retailers with attractive, modern storefront signs (that they could otherwise not afford) that bear cigarette advertisements. ${ }^{32}$ These strategies will likely increase in importance as the 2003 advertising ban excludes point of sale. Currently, there are no regulations regarding point of sale advertising. Tobacco products and advertisements are commonly placed next to candies and snacks easily accessible to minors. Similar to women, portrayal of smoking by Indian actors also encourages smoking for children and adolescents. ${ }^{28}$

\section{Circumventing the advertising ban}

Cigarette manufacturers are employing various strategies that may work to ensure continued successful marketing of their products after the advertising ban. After the passage of Tobacco Bill 2003 but before its implementation in May 2004, new mobile billboards (billboards on a truck) appeared in different parts of the city in high traffic areas usually in close proximity to the advertisements for competing brands (fig 10). In addition to strengthening their existing brands through increased advertising, the tobacco companies are also launching new brands that are extensions of the previously marketed products. For example, ITC launched Wills Silk Cut, an extension of its Wills Navy Cut brand, with a new flavour and filter. Establishing a strong brand image before the enforcement of the ban is crucial to ensure continued successful marketing of these products.

In addition, brand imagery can be communicated without reference to cigarettes. This is evident in the evolution of the current Four Square campaign. Some of the Four Square campaign storefront and bus stop advertisements contain the black and white photograph with a man holding a red square on one end and an open pack of cigarettes on the other; others just contain the photograph with the text, "four square the man with the smooth edge" and three red squares. The Four Square billboards, posters, and magazine advertisements are composed solely of the photograph, the logo, and the slogan; the only mention of cigarettes is in the statutory warning. Furthermore, it is not uncommon to see the black and white photograph without any text mentioning Four Square or statutory warning (fig 2). The image and its association with Four Square cigarettes is clearly recognisable. When the advertising ban is in effect, these images could be used to continue to promote Four Square cigarettes. The campaign depicts "the man with the smooth edge" holding a red square in his hand and the colour red is said to aid recall of a product. ${ }^{32}$

Furthermore, to ensure "constant reinforcement of brand positioning" 22 tobacco companies promote trade diversification. In July 2000, ITC launched its first Wills Lifestyle clothing retail store in New Delhi, and today there are 48 stores across India. ${ }^{33}$ The initial offering of Wills Sport was with Wills sponsorship of cricket tournaments. Since then it has launched Wills Classic formal and social evening wear, Wills Clublife, evening wear, and most recently John Players men's clothing. Wills Lifestyle clothing promotes a sophisticated and western image similar to ITC tobacco products and targets the same consumer as the super premium and premium cigarette brands. The advertisements are similar in their layout, colour scheme, and themes; both the Wills Lifestyle and Wills Silk Cut billboards use the same sky blue background and one of the Lifestyle advertisements depict a couple similar to the Wills "made for each other" campaign (fig 3 and 4). Lastly, names that have been associated with cigarette trade in the past are being used for the Lifestyle clothing line-for example, John Players, a mid price clothing segment for men, was the name of a prominent British tobacco company (John Player and sons).

\section{What this paper adds}

The World Health Organization projects that tobacco use may account for more than 1.5 million deaths in India by 2020, and the Tobacco Institute of India estimates that cigarette consumption will continue to increase by $5 \%$ per year. Despite this steady and substantial increase in tobacco use in India, there are few studies describing current cigarette marketing strategies in India, and no studies detailing the market segmentation.

We conducted a pilot study to describe cigarette market segmentation by socioeconomic status in Mumbai, India in September 2003. We found that cigarette advertising was ubiquitous in the outdoor environment, and present in news and film magazines but not in women's magazines or the newspapers in Mumbai, India. We describe new sophisticated campaigns that appear to target men, women, and children in different socioeconomic groups in Mumbai. Many of these strategies circumvent the Indian advertising ban. Understanding these marketing strategies is critical to minimise the exploitation of loopholes in tobacco control legislation.

Strategies similar to those previously employed in other nations are being used in India. In Australia, "new brands were launched in the dying days of above the line" marketing "in an attempt to create brand awareness before the market became darker". ${ }^{22}$ Similarly, ITC launched both Insignia and Wills Silk Cut at a time when Tobacco Bill 2003 had been passed by both houses of the parliament and was awaiting the President's signature. ${ }^{34}$ Although tobacco manufacturers deny use of trademark diversification to promote tobacco products, brand stretching is another strategy commonly used "to extend the reach of their trademarks well outside the tobacco category...for constant reinforcement of brand positioning. ${ }^{135}$ In addition to its Wills Lifestyle clothing, ITC has diversified its portfolio to include hotels, paperboard, and specialty paper production, and products in branded packaged foods (Aashirwaad Readymeals), greeting cards (Expressions Paperkraft), and school stationery (Classmates). ${ }^{36}$

Another successful strategy used by the tobacco companies is product placement. The WHO "study on the portrayal of tobacco in Indian Cinema" reported that there was some form of tobacco portrayal in $76 \%$ of the films reviewed from 1991-2002 with cigarette use accounting for $72 \%$ of all smoking incidents. ${ }^{28}$ Given that India produces more than 900 movies per year that attract 15 million viewers a day, in addition to the indirect exposure across the world via satellite television and pirate copies, this will likely be an effective strategy to popularise tobacco use and circumvent the advertising ban.

Although passage of Cigarettes and Other Tobacco Act 2003 is a significant event in tobacco control, it will be effective only if it is strictly enforced. "Enforcement has been difficult and complex because of existing practices. Adults usually send their children to buy the tobacco products and very often the sales-person is underage too. ${ }^{\prime 37}$ It is likely that cigarette companies will be further able to overcome advertising restrictions by finding loopholes in tobacco legislation. In other countries, tobacco companies have advertised in international publications or sponsored international events in nations where tobacco advertising or sponsorship is banned. Similar tactics may be employed in India if the Indian government is not vigilant.

This study is an important contribution in that there are few studies assessing cigarette marketing in India. However, it was limited in that it was an observational study, 
conducted over a short period of time, and there was lack of census data that allowed a clear distinction of the SES populations. Lastly, conclusions of this study are only relevant to Mumbai as India is a diverse nation and cigarette brands and marketing strategies tend to be region specific.

Tobacco related morbidity and mortality is on the rise in India as is tobacco marketing. In this study, we conclude that cigarette manufacturers are targeting all SES segments, women and youth. Furthermore, although India has made tremendous progress in tobacco legislation, cigarette manufacturers are working to ensure continued brand and market presence. It is imperative that anti-tobacco public health education campaigns are implemented especially targeting lower SES segments, women, and youth and exposing the tobacco industry's subtle strategies enticing them. The Indian government will need to be stringent in its implementation of the Cigarettes and Other Tobacco Products Act, 2003, mindful of the loopholes and passing new legislation to combat these and vigilant in ensuring that cigarette manufacturers are not targeting minors.

\section{ACKNOWLEDGEMENTS}

The authors wish to thank Professor Timothy Dewhirst for sharing his cigarette advertising coding instrument and Professor Stanton Glantz for helpful comments on the manuscript.

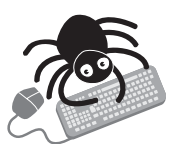

To view figs 1-10 please visit the Tobacco Control website-hitp://www.tobaccocontrol.com/ supplemental

\section{Authors' affiliations}

R Bansal, P M Ling, Department of Medicine, Division of General Internal Medicine, Center for Tobacco Control Research and Education, University of California, San Francisco, San Francisco, California, USA S John, PATH Canada, Mumbai, India

This work was supported by National Cancer Institute Grant number CA87472 and the University of California San Francisco Department of Medicine.

Competing interests: none declared

\section{REFERENCES}

1 Arora M. The tobacco journey: seeds of a menace. Health for the millions June-September, 2003:4-6.

2 Shimkhada R, Peabody JW. Tobacco control in India, Policy and Practice. Bulletin of World Health Organization 2003;81:48-52.

3 World Health Organization. Tobacco or health: a global status report. Geneva: WHO, 1997

4 Rani M, Bonu S, Jha $\mathrm{P}$, et al. Tobacco use in India: prevalence and predictors of smoking and chewing in a cross sectional household survey. Tobacco Control 2003;12:e4.

5 Sinha DN. Exposure versus targeting youth in the north and east of India. Health for the millions June-September, 2003:4-6.

6 Murray $\mathrm{CJ}$, Lopez AD, eds. The global burden of disease: a comprehensive assessment of mortality and disability from diseases, injuries and risk factors in 1990 and projected to 2020. Cambridge, Massachussets: Harvard School of Public Health, 1996
7 The World Bank. Curbing the epidemic. Governments and economics of tobacco control. Washington DC: The World Bank, 1999.

8 Tuinstra T. The end of the tunnel. Tobacco Reporter 1998:4.

9 Mackay J, Amos A. Women and tobacco. Respirology 2003;8:123-30.

10 Srivastava $\mathbf{A}$. The role and responsibility of media in global tobacco control. The WHO international conference on global tobacco control law: towards a WHO framework convention on tobacco control, January 7-9, 2000, New Delhi, India.

11 Baxi S. Gold Flake bags gold in FMCG brand race. The Economic Times. December 18, 2002.

12 Anon. The Cigarettes and other Tobacco Products (Prohibition of advertisement and regulation of trade and commerce, production, supply and distribution) Act, 2003, Health for the millions, June-Sept. 2003.

13 Vaidya SG, Vaidya JS, Naik UD. Sports sponsorship by cigarette companies influences the adolescent children's mind and helps initiate smoking: results of a national study in India. J Indian Med Assoc 1999;97:354-6, 359

14 Vaidya SG, Vaidya JS. Tobacco sponsorship of Formula One motor racing. Lancet 1998:351:452.

15 Anon. Print has grown by $8 \%$ in urban India. Times of India December 22, 2003.

16 Bhusahn R. Red \& White Awards ads shift focus, Business Line Internet edition, Financial Daily from The Hindu, November 122002.

17 Hammond R, Rowell A. Trust Us, We're the Tobacco Industry. http:// www.ash.org.uk/html/conduct/html/trustus.html, May, 2001

18 ASH UK. Tobacco explained: the truth about the tobacco industry .... in its own words. Action on Smoking and Health UK. http://www.ash.org.uk/html/ conduct/pdfs/tobexp.pdf, June, 1998.

19 Carter SM. The Australian cigarette brand as product, person, and symbol. Tobacco Control 2003;12(suppl III):iii79-86.

20 Gilmore AB, McKee M. Moving East: how the transnational tobacco industry gained entry to the emerging markets of the former Soviet Union-part I: establishing cigarette imports. Tobacco Control 2004;13:143-50.

21 Chapman S. "The contemporary, irreverent brand of youth with an independent streak": BAT's youth promotions in Myanmar. Tobacco Control 2004; 13:93-4.

22 Carter SM. Going below the line: creating transportable brands for Australia's dark market. Tobacco Control 2003;12(suppl III):iii87-94.

23 Dewhirst T, Hunter A. Tobacco sponsorship of Formula One and CART auto racing: tobacco brand exposure and enhanced symbolic imagery through cosponsors' third party advertising. Tobacco Control 2002;11:146-50.

24 Amos A, Haglund M. From social taboo to "torch of freedom": the marketing of cigarettes to women. Tobacco Control 2000:9:3-8.

25 Reynolds C. Tobacco advertising in Indonesia: "the defining characteristics for success". Tobacco Control 1999;8:85-8.

26 Mackay J, Eriksen M. The tobacco atlas. Geneva: World Health Organization, 2002.

27 Aghi MB. Women's participation in health policy formulation in India: Towards Promulgation of Cigarette and other Tobacco Products Bill, Presented at a Panel Discussion on Health Policy in Geneva, Switzerland, October 9-12 2001.

28 World Health Organization. Bollywood: victim or ally, a study on the portrayal of tobacco in Indian cinema, WHO publication, 2003.

29 Simpson D. India: movie shoots at women. Tobacco Control 2000;9:9-15.

30 Donovan RJ, Jancey J, Jones S. Tobacco point of sale advertising increases positive brand user imagery. Tobacco Control 2002;11:191-4.

31 Price Waterhouse Coopers. The tobacco industry India: an economic analysis, Price Waterhouse Coopers, November, 2000

32 Kaufman N, Nichter M. The Marketing of tobacco to women: global perspectives, 2001. In: Samet JM, Yoon SY, eds. Women and the tobacco epidemic: challenges for the 21 st century. Geneva: World Health Organization, 2001, http://www.who.int/tobacco/media/en/ WomenMonograph.pdf.

33 ITC Limited. Lifestyle retailing. http://www.itcportal.com/sets/ lifestyle_frames.html (Accessed 28 June 2004).

34 Sen S. http://www.rediff.com/money/2003/jul/19ban.htm, July 19, 2003.

35 Stockale B. Australia trip: tapline learning (highly restricted market) 12 Feb. 1997. Reynolds RJ. Bates No. $518093846 / 3852$ http:// legacy.library.ucsf.edu/tid/ads90d00.

36 ITC Limited. One of India's Most Valuable Corporations. http:// www.itccorporate.com/ (Accessed 29 June 2004).

37 Aghi M, Sanchez S. South and South East Asia: in stage II of the tobacco epidemic, The Net Spring, 2004. 